\title{
Preface to the special issue on the 2008 great Wenchuan earthquake*
}

\author{
Xiaofei Chen * \\ School of Earth and Space Science, University of Science and Technology of China, Hefei 230026, China
}

On 12 May 2008, about one year ago, a devastating earthquake $\left(M_{\mathrm{S}} 8.0, M_{\mathrm{W}} 7.9\right)$ struck the eastern margin of the Tibetan plateau in west China, its vast energy swept across the most of areas of Chinese mainland at 14: 28: 04 of Beijing Time (06:28:01.42 UTC) as reported by China Earthquake Networks Center. The meizaseismal area was identified to be in the Wenchuan Yingxiu-Beichuan area of the west Sichuan lying on the northeast-striking Longmenshan thrust belt, the estimated earthquake rupture extended to more than $300 \mathrm{~km}$, mainly along northeastern direction, with a complicated slip history (Chen et al, 2008; Zhang et al, 2009; Wang et al, 2008; Ji and Hayes, 2008; Burchfiel et al, 2008). The coseismic slip consists of thrust- and right-lateral slip components, respectively, in the southern and middle segments and the northern segment of the rupture (Chen et al, 2008; Zhang et al, 2009; Wang et al, 2008; $\mathrm{Ji}, 2008$ ), and reaches two peaks underneath the Wenchuan-Yingxiu ( $\sim 7.3 \mathrm{~m})$ and Beichuan $(\sim 5.6 \mathrm{~m})$, respectively, according to Zhang et al (2009). Obviously, the largest slip occurred around the focal area from which the great earthquake initiated. The great Wenchuan earthquake, caused 87150 deaths or missing, nearly 4 million injured and 100 billion RMB yuan property loss (National Wenchuan Earthquake Expert Committee, 2008), is the most disastrous earthquake to hit China since the magnitude 7.8 Tangshan earthquake of 1976.

In the viewpoint of tectonics, the vast energy released by Wenchuan earthquake had been accumulated for thousands years within Longmenshan fault zone due to the continuous eastward strong stressing driven by the extrusion of India plate to Tibetan plateau (Burchfiel et al, 2008). This earthquake results in large-scale landslides and debris flows, silting of rivers and more than 3000 barrier lakes and seriously damaged more than one

\footnotetext{
* Received 2 April 2009; accepted in revised form 4 April 2009; published 10 April 2009.

^Corresponding author.e-mail: xfchen1@ustc.edu.cn
}

hundred of cities and towns. A large number of buildings, including houses, roads and bridges were destroyed or collapsed. Such severe induced geological hazards in Wenchuan earthquake are partially due to the rapidly varied topography there. A preliminary simulation of ground motion, incorporating three-dimensional earth structure, complex finite-fault rupture and realistic surface topography, for Wenchuan earthquake conducted by Zhang et al (2008) using a new simulation technique (Zhang and Chen, 2006) has revealed that although the fault rupture and basin structure control the overall pattern of the peak ground shaking, strong scattering effects by the rough topography above the rupture fault result in significantly larger peak ground motion on the apex of topographic relief than in the valley. These results imply that the rough topography which modulates systematically the pattern of ground shaking is likely one of the factors induced the massive landslides and barrier lakes. Therefore, the topographic effects should be taken into account in making a localized seismic hazard assessment in places of rough topography.

As other great earthquakes, Wenchuan earthquake is scientifically important for the study of earthquake science. Numerous invaluable seismological, geological, geodesic and hydraulic data were acquired during and after the mainshock. They will sever the scientists to investigate in-depth the physical mechanism of this great earthquake for a while. Immediately after Wenchuan earthquake, Chinese seismologists actively engaged in the various field observations, data acquisitions, and analysis and studies on this quake in a variety of issues, and obtained some preliminary results. As a journal dedicated to the study of earthquake science, we organize this special issue on the Wenchuan Earthquake to present some research progress made by Chinese colleagues recently.

In this special issue on Wenchuan earthquake, we 
selected 10 papers with a variety of topics: from seismicity characteristics (Zhang et al) to short-term and imminent geomagnetic anomalies (Wang et al) before the mainshock; from the coseismic responses of groundwater levels in the Three Gorges well-network (Liu et al) and the Tangshan well (Yin et al) to the spatio-temporal variation of this earthquake sequence (Cheng et al.); and from the rapid aftershock strong motion observation (Wen et al) and earthquake geological and engineering survey (Zhao and $\mathrm{Xu}$; Sun et al) to the rapid assessment (Wang et al) and death toll estimation improvement $(\mathrm{Xu}$ and $\mathrm{Gu})$. These are only parts of and preliminary studies on Wenchuan earthquake, we certainly welcome more in-depth studies on this earthquake by scientists around the world in the future.

\section{References}

Burchfiel B C, Royden L H, van der Hilst R D,,Hager B H, Chen Z, King R W,
Li C, Lü J, Yao H, and Kirby E (2008). A geological and geophysical context for the Wenchuan earthquake of 12 May 2008, Sichuan, People's Republic of China. GSA Today, 18(7): 4-11.

Chen Y T, Xu L S, Zhang Y, Du H L, Feng W P, Liu C, Li C L and Zhang H X (2008). Report on the great Wenchuan earthquake source of May 12, 2008. http:// www.csi.ac.cn/sichuan/chenyuntai.pdf (in Chinese).

China Earthquake Networks Center, 2008-05-12. Retrieved on 2008-05-14.

Ji C and Hayes G (2008). Preliminary result of the 12 May $2008 M_{\mathrm{W}} 7.9$ western Sichuan China earthquake. http://earthquake.usgs.gov/eqcenter/eqithere news/2008/us2008ryan/finite_fault.php.

National Wenchuan Earthquake Expert Committee (2008). Earthquake-Geological Disaster Atlas of Wenchuan Earthquake Area. Beijing: SinoMaps Press, 1-105.

Wang W M, Yao Z X and Zhao LF (2008). Source rupture process of $M_{\mathrm{S}} 8.0$ Wenchuan earthquake. http://www.cnetnews.com.cn/2008/0519/869550.shtml.

Zhang W and Chen X F (2006). Traction image method for irregular free surface boundaries in finite difference seismic wave simulation. Geophys J Int, 67: 337-353.

Zhang W, Shen Y and Chen X F (2008). Numerical simulation of strong ground motion for the $M_{\mathrm{S}} 8.0$ Wenchuan earthquake of 12 May 2008. Sci China (Series D), 51(12): 1 673-1 682.

Zhang Y, Feng W P, Xu LS and Chen Y T (2009). Temporal-spatial rupture process of the 2008 great Wenchuan earthquake., Sci China (Series D), 52(2): 145-154. 